\title{
Por um novo modelo de professor: os livros publicados pela Cades
}

\author{
Searching a new model for teachers: the books published by the Cades
}

\author{
Bruna Camila Both Miranda ${ }^{1}$ \\ Antonio Vicente Marafioti Garnica ${ }^{2}$
}

\begin{abstract}
Resumo
O presente artigo, inscrito no campo da História da Educação Matemática, apresenta um estudo sobre as obras publicadas pela Campanha de Aperfeiçoamento e Difusão do Ensino Secundário (Cades), de modo especial aquelas voltadas ao ensino de Matemática. Defendemos que tais obras - junto a outras ações implementadas pela Campanha - foram uma tática da Cades para criar um novo modelo de professor secundário no Brasil, nas décadas de 1950 e 1960, quando tanto o mercado quanto o contexto político e social exigiam alterações fundamentais na escola e nas práticas pedagógicas de seus professores.
\end{abstract}

Palavras-chave: Campanha de Aperfeiçoamento e Difusão do Ensino Secundário; Formação de professores; Ensino Secundário; Livros de didática.

\begin{abstract}
This paper, developed according to an historiographical approach, has as its main objective to study the books produced by Cades - the Campaign for the Improvement and Diffusion of Secondary Education created by the Brazilian federal Government to disseminate and improve higher education in Brazil. A particular discussion is done focusing the titles related to Math teaching and learning. We argue that the many books published by the Campaign - among other many actions also sponsored by Cades - were part of a broader intention aiming to create a new model of teacher for the secondary education in Brazil during the Fifties and Sixties.
\end{abstract}

Keywords: Campaign for the Improvement and Diffusion of Secondary Education (Cades); Teachers formation; Secondary Education in Brazil; Didactical books and textbooks.

\section{Introdução}

A Campanha de Aperfeiçoamento e Difusão do Ensino Secundário (Cades) foi uma estratégia ampla, tanto temporal (esteve em atuação por quase 20 anos: criada na década de 1950, manteve-se em funcionamento até início de 1970) quanto espacialmente (atuou nas diversas regiões brasileiras, atendendo, por meio de diferentes frentes, especialmente aos profissionais de cidades do interior, distantes dos grandes centros). A Campanha visava a apoiar a formação de professores das mais diversas áreas, bem como assessorar diretores, inspetores e secretários de escolas.

\footnotetext{
Submetido em: 15/12/2018 - Aceito em: 26/03/2019 - Publicado em: 30/03/2019

${ }^{1}$ Doutora em Educação Matemática pela Universidade Estadual Paulista “Julio de Mesquita Filho" (Unesp) Rio Claro (SP), Brasil. E-mail: bruna_both@hotmail.com.

2 Doutor em Educação Matemática pela Unesp de Rio Claro, Livre-docente pelo Departamento de Matemática da Unesp de Bauru, docente da Unesp - Bauru (SP), Brasil, e dos Programas de Pós-Graduação em Educação Matemática da Unesp, Rio Claro (SP), e Educação para a Ciência da Unesp, Bauru (SP), Brasil. E-mail: vicente.garnica@unesp.br.
} 
DOI: https://doi.org/10.20396/zet.v27i0.8654273

A atuação da Cades ocorre em um período de profundas transformações na sociedade brasileira, vindo a atender e promover, particularmente, a expansão do Ensino Secundário, tendo como pressuposto que o ensino praticado até então não atendia mais as necessidades que se impunham naquele cenário. Além disso, o número de professores graduados, à época, era diminuto, visto a formação superior ser recente, iniciada na década de 1930, tendo por muito tempo ficado restrita aos grandes centros. Diante disso, a Cades foi criada com o objetivo de aperfeiçoar e difundir o Ensino Secundário, segundo sua própria nomenclatura explicita.

O estudo das diferentes frentes de ação dessa Campanha nos levou a compreender que sua intenção central era a criação de um novo modelo de professor secundário, que atendesse às novas demandas da sociedade e de uma escola a ser renovada. Para isso, várias táticas ${ }^{3}$ foram colocadas em funcionamento, dentre as quais a publicação de livros de variadas temáticas relativas ao Ensino Secundário, mas, especialmente, a publicação intensa de obras voltadas à formação de professores.

Os resultados que apresentamos neste texto são recortes de uma pesquisa mais ampla, de natureza historiográfica ${ }^{4}$, o que torna necessário expor, ao menos minimamente, alguns de nossos pressupostos sobre isso. As práticas historiográficas se dão a partir de fontes de diferentes naturezas, não sendo nossa intenção restringir as fontes mobilizadas, ainda que saibamos não haver fontes nem acervos suficientes que deem conta de criar a verdade de algo (uma situação, uma instituição, um personagem, um espaço, um tempo etc). As fontes são resíduos do passado, podendo tanto estar disponíveis desde um tempo ao qual não temos acesso quanto podem ser criadas - como registros de memórias de um passado - no presente. A História é uma invenção do presente que se ampara em resíduos do passado. A História é um discurso do presente sobre o passado e não meramente um estudo do passado. $O$ passado é "inventado a partir do presente, [e] só adquire sentido na relação com este presente que passa e, portanto, anuncia já a sua morte prematura”. Com isso, História e passado são sempre em processo, "como um abismo que não se para de cavar" (Albuquerque Jr., 2007, p.61) ou um "labirinto de corredores e portas contíguas, aparentemente todas semelhantes, mas que, dependendo da porta que o sujeito escolhe para abrir, pode estar provocando um desvio, um deslizamento para um outro porvir" (Albuquerque Jr., 2007, p.73) pois, a partir dos dados que temos disponíveis, muitas interpretações são possíveis e, então, muitas histórias podem ser contadas.

Na História o objeto de estudo não existe a priori, são a proposição do estudo e o

\footnotetext{
${ }^{3}$ Táticas, no léxico, referem-se a ações que visam a possibilitar que algumas estratégias se efetivem. Podemos, a partir disso, afirmar que se a Cades tinha como intenção estratégica criar um novo modelo de professor secundário, essa criação demandava ações mais locais e pontuais junto aos agentes da educação (secretários, técnicos, diretores, professores), aos alunos e a toda comunidade escolar: as táticas. Exemplos dessas táticas no sentido que aqui optamos por defender - são os cursos de treinamento e atualização, a realização de eventos vários, concursos, publicação e distribuição (gratuita) de revistas e livros etc.

${ }^{4}$ As pesquisas historiográficas apresentam "um interesse de pesquisa, a formulação de questões históricas legítimas, um trabalho com os documentos e a construção de um discurso que seja aceito pela comunidade." (Valente, 2007, p.32).
} 
DOI: https://doi.org/10.20396/zet.v27i0.8654273

início da investigação que o criam, são as pesquisas relacionadas a ele que o caracterizam como tal. "Assim, o método histórico envolve a formulação de questões aos traços deixados pelo passado, que são conduzidos à posição de fontes de pesquisa por essas questões, com o fim da construção de fatos históricos ${ }^{5}$, representados pelas respostas a elas." (Valente, 2007, p.32).

Desse modo, utilizamos fontes que pudessem nos ajudar a atender nosso objetivo, realizamos diversas leituras de materiais produzidos pela Cades, da legislação, de notícias de jornais da época que abordavam a Campanha e de outras publicações que, de algum modo, tratavam dela. Além dessas fontes, também operamos com autores que nos ajudaram a compreender e discutir aspectos que julgamos relevantes para o que buscávamos compreender. Diante desses estudos, com nosso objetivo em mente, questionamos e analisamos os livros publicados pela Cades de modo a defender a construção de um modelo de professor secundário como a intenção central da Campanha. Ainda que a Cades tenha, além dos cursos e manuais para formação de professores também se lançado à organização de outros eventos e iniciativas voltadas à comunidade escolar (estudantes, diretores, secretários e orientadores educacionais, por exemplo), neste artigo - dada a natureza temática dessa edição da Zetetiké - trataremos apenas dos manuais escolares por ela produzidos.

Isso posto, passamos a apresentar aqui algumas de nossas elaborações/conclusões que não são apenas uma narrativa acerca das publicações da Cades e da construção de um modelo de professor secundário, mas também o resultado da "identificação e construção de fontes" que, após passarem por "processos interpretativos", deram "consistência ao objeto histórico" (Valente, 2007, p.36) produzido.

\section{Os manuais pedagógicos}

A palavra impressa foi uma marca importante no processo anterior e posterior à Revolução Francesa (1789). Por meio da palavra escrita foram difundidos os ideais revolucionários liberais pelo mundo. Ao mesmo tempo, os revolucionários souberam utilizá-la como uma estratégia de reorganização das instituições do novo regime e a escola foi um dos lugares onde a palavra impressa difundiu-se por meio de uma cultura escolar na qual o livro tornou-se um objeto estratégico para a difusão da racionalidade e da ciência. (Almeida Filho, 2008, p.23).

Os manuais pedagógicos, de modo geral, têm como foco o "ensinar a ensinar", operando como uma gramática do magistério na qual se articulam os modos de conceber e agir nessa profissão. As primeiras edições desses manuais são contemporâneas dos movimentos iniciais de formação de professores destinados a atuar nas escolas populares

\footnotetext{
${ }^{5}$ Fatos históricos, aqui, são entendidos por nós como histórias que podemos contar a partir dos estudos que realizamos. Para isso, nos valemos de "todos os registros que foram possíveis de ser conhecidos. Sem negarmos a materialidade do evento, mas não sendo guiados por ele, pois esses só se 'tornam', efetivamente, 'eventos', 'fatos', 'acontecimentos' quando a eles atribuímos significados, quando deles falamos, quando lhes damos um contorno, quando os moldamos num tempo e num espaço, a partir de nossas narrativas (e/ou daqueles que neles viveram e que permitiram/proporcionaram o registro de suas narrativas). Sem isso, 'os fatos' não seriam nada além de lembranças perdidas, memórias esquecidas, passado.” (Morais, 2012, p.28).
} 
DOI: https://doi.org/10.20396/zet.v27i0.8654273

(Silva, 2005). Até onde se tem notícia, o mais antigo manual, publicado no Brasil ${ }^{6}$, destinado à formação de professores, é o Compêndio de Pedagogia, de Antônio Marciano da Silva Pontes, cuja primeira edição é de 1874.

Até os anos 1920, os manuais pedagógicos eram, em geral, assinados por autores estrangeiros, de modo especial franceses e portugueses, sendo que apenas na década de 1930 é que as obras nacionais começam a se fazer mais presentes (Silva, 2005). ${ }^{7}$ A partir dessa década, as reformas educacionais que se seguiram (a Reforma Francisco Campos, em 1931, a Lei Orgânica do Ensino Secundário, de 1942, e a Lei de Diretrizes e Bases, de 1961) visando à difusão da escola pública, à formação dos professores para nela atuarem e à necessidade constante de atualização pedagógica estimularam uma literatura específica, voltada à formação renovadora de professores (Schmidt, 2006).

Na década de 1940, embora já houvesse variadas publicações voltadas à educação, ainda era sensível a carência de materiais que servissem de recurso para a formação de professores (Almeida Filho, 2008). Eivlys Helvetia Mabilde, autora da obra Didática Especial de Ciências Naturais ${ }^{8}$, por exemplo, aponta que, de modo geral, os livros destinados aos professores eram muito teóricos, com poucas aplicações práticas, não indicando diretamente como ensinar, como proceder em sala, enfim, não promovendo de forma adequada estratégias voltadas à prática cotidiana dos professores.

Entre os anos 1940 e 1970 sente-se uma alteração nesse panorama: os livros voltados à formação de professores passam a ter como foco os métodos didáticos, privilegiando "a explicação de como planejar as aulas, ordenar os conteúdos, usar técnicas de ensino ou avaliar o rendimento dos alunos" (Silva, 2005, p.274) ${ }^{9}$, uma tendência sentida tanto em nível nacional como internacional. Nas décadas de 1940 e 1950, o escolanovismo deu espaço a "argumentos mais sintéticos, prescritivos, desenvolvidos em parágrafos mais curtos e usando frases de fácil entendimento" (Silva, 2005, p.274). Essa mudança também está relacionada à

\footnotetext{
${ }^{6}$ De acordo com Silva (2005).

7 Até os anos de 1920, os livros de autores brasileiros, ainda em pequeno número, eram impressos, em sua maioria, no exterior, o que tornava bastante complicada e onerosa a publicação que, em boa parte das vezes, era custeada pelo próprio autor. Nesse período, no Brasil, a editoração era realizada, em geral, por um pequeno número de imigrantes (nessa época o papel brasileiro também não era de boa qualidade, o que agravava ainda mais o quadro de editoração nacional). Nos anos de 1930 essa realidade começou a mudar, com mais brasileiros assumindo esse mercado, especialmente nos maiores centros urbanos, como São Paulo, Rio de Janeiro, Porto Alegre e Belo Horizonte. Até os anos de 1920 existiam no país cerca de trinta livrarias, mas a partir de iniciativas como a de Monteiro Lobato, os livros passaram a ser vendidos em diferentes estabelecimentos comerciais, como farmácias, papelarias e armazéns, ampliando para cerca de 2.000 o número de distribuidores no país. Nesse período, Monteiro Lobato também modernizou o modo de divulgação das obras, passando a anunciá-las em jornais, contrariando o que se fazia até então, com divulgação boca-a-boca pelo livreiro, quando "ler, comprar e frequentar livrarias eram ainda e sobretudo símbolos de distinção, utilizados com esmero pela elite pensante" (Pontes, 1988, p.62). A ampliação das publicações nacionais na década de 1930 está intimamente relacionada à crise econômica mundial de 1929, que encareceu a importação e tornou o livro nacional mais competitivo em seu próprio mercado (Hallewell, 1985).

${ }^{8}$ Publicação da Campanha de Aperfeiçoamento e Difusão do Ensino Secundário (Cades) em fins dos anos 1950, a partir do Concurso Dia do Professor, também promovido pela Campanha.

${ }^{9}$ Segundo Silva (2005), no Brasil esse movimento ficou conhecido como tecnicização do ensino.
} 
DOI: https://doi.org/10.20396/zet.v27i0.8654273

expansão do ensino iniciada nesse período em que a população passou a ser atendida mais amplamente em seus anseios quanto à Educação. Esse crescimento também ocasionou o aumento do número de cursos de formação de professores e uma consequente mudança na concepção, organização e prática do ensino até então oferecido. Assim, destinando-se a um público cada vez maior, os manuais pedagógicos passaram a apresentar um conteúdo mais acessível, visando, também, atender aos docentes ingressantes na carreira do magistério.

A intensificação na publicação de impressos destinados à formação de professores deu-se, portanto,

durante a constituição de sistemas de ensinos públicos, obrigatórios, gratuitos e organizados pelo Estado. [...] Os manuais foram [...] produtos da escola feita para 0 povo, ao mesmo tempo em que explicaram a composição do cotidiano nessa instituição, ou seja, as atribuições do docente, as atividades do aluno, o funcionamento das aulas, a organização dos conteúdos, os métodos didáticos. (Silva, 2005, p.53).

Entre 1941 e 1970 o Estado foi o principal produtor de manuais e periódicos voltados à formação de professores (Schmidt, 2006). A partir desse período, nota-se uma alteração radical na produção editorial que de quase artesanal torna-se, cada vez mais, uma indústria moderna. Durante o governo Juscelino Kubitschek (1956-1961) houve grande incentivo ao setor editorial, que, à época, cresceu cerca de $150 \%$. Também nessa época, o processo de impressão modernizou-se ainda mais, permitindo alterações significativas quanto ao aspecto gráfico dos livros (Silva, 2005), de modo que, na década de 1960, o mercado editorial estava vivamente reanimado.

Ao considerar-se o cenário educacional em expansão, especialmente a partir da década de 1940, com as ainda escassas instituições para formar professores para o Ensino Secundário, tem-se que os manuais pedagógicos se tornaram um dos mais importantes meios para a "difusão de idéias pedagógicas e de inovações metodológicas, orientando as práticas nas escolas" (Garcia \& Nascimento, 2009, p.8.638).

\section{Os manuais/livros publicados pela Cades}

Os livros publicados pela Cades visavam, de modo geral, à formação de professores. Nesse sentido, tratavam de temáticas corriqueiras, como aquelas relativas a aspectos didáticos, curriculares e legais das diversas áreas do Ensino Secundário. Além disso, ajudavam a "divulgar estratégias de ensino, preparar para os exames de suficiência e orientar a gestão das unidades escolares" (Baraldi \& Gaertner, 2013, p.29). Também foram publicadas obras visando a um aperfeiçoamento da Escola Secundária como um todo, dentre as quais devem ser ressaltadas aquelas voltadas à orientação educacional, que tratam tanto das relações escola-família quanto da organização escolar. Além destas, foram publicados livros de educação cívica e manuais para tratar de aspectos específicos de algumas áreas, como as obras relativas à nomenclatura gramatical brasileira e à notação e nomenclatura de Química inorgânica. 
DOI: https://doi.org/10.20396/zet.v27i0.8654273

Em Baraldi e Gaertner (2013) ${ }^{10}$ encontramos uma listagem dos livros publicados por essa Campanha. Até o ano em que foi publicado esse estudo, foram localizadas pelas autoras 106 obras $^{11}$, das quais sete eram voltadas à Matemática. Posteriormente, identificamos mais alguns livros não citados nessa relação ${ }^{12}$ (Quadro 1$)^{13}$.

Quadro 1 - Livros publicados pela Cades (complemento a Baraldi \& Gaertner, 2013). Continua.

\begin{tabular}{|c|c|c|}
\hline Título & Autor & $\begin{array}{c}\text { Ano de } \\
\text { publicação }\end{array}$ \\
\hline Didática Especial Prática de Ensino & Maria Celisa Costa Couto & - \\
\hline Didática Especial de Ciências Naturais & Eivlys Helvetia Mabilde & - \\
\hline Didática Especial da Química & José Murad & 1959 \\
\hline 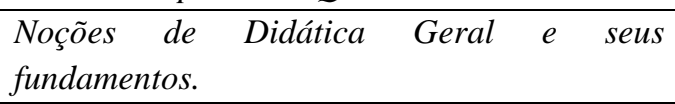 & $\begin{array}{l}\text { Um grupo de orientadores dos cursos } \\
\text { da Cades. }\end{array}$ & 195-? \\
\hline $\begin{array}{l}\text { Anteprojeto de simplificação e unificação da } \\
\text { nomenclatura gramatical brasileira }\end{array}$ & - & 1957 \\
\hline Apostilas de Didática Especial de Português ${ }^{14}$ & - & - \\
\hline Apostilas de Didática Especial de Latim & - & - \\
\hline Apostilas de Didática Especial de Inglês ${ }^{15}$ & - & - \\
\hline Apostilas de Didática Especial de Desenho ${ }^{16}$ & $\begin{array}{c}\text { Alcidio Mafra de Souza, Ecyla } \\
\text { Castello Branco da Cruz, Maria } \\
\text { Isabel de Souza Costa e Roberto } \\
\text { Magrassi Nicolini. }\end{array}$ & 1958 \\
\hline
\end{tabular}

Fonte: Elaboração pessoal.

${ }^{10}$ Nessa referência há uma análise geral acerca dos livros voltados ao ensino de Matemática. Além dessas análises, uma mais completa acerca da obra Como Ensinar Matemática no Curso Ginasial: manual para orientação do candidato a professor de curso ginasial no interior do país (Cades, 195-?) foi realizada por Lopes (2015).

${ }^{11}$ Muitas dessas obras foram frutos do Concurso Dia do Professor, organizado pela Cades. Essas obras possibilitaram que se aumentasse consideravelmente a bibliografia especializada produzida no país.

${ }^{12} \mathrm{~A}$ maioria das obras da Cades que localizamos foram publicadas durante a primeira gestão de Gildásio Amado como diretor do Ensino Secundário (1956-1963). No entanto, até abril de 1956 a Campanha já havia elaborado oito manuais direcionados aos docentes, além da impressão de "mais de vinte publicações sôbre aspectos técnicos e administrativos do ensino" (Armando..., Diário Carioca, 1956, p.3). Já para o ano de 1960, foram incluídas 32 publicações em seu programa de ações (Presença..., Jornal do Commercio, 1960).

${ }^{13}$ Além destes, também localizamos outras edições de livros já citados em Baraldi e Gaertner (2013).

${ }^{14}$ Quanto a essas quatro últimas obras, Apostilas de Didática Especial de Português, de Latim, de Inglês e de Desenho, no livro de Baraldi e Gaertner (2013) há também referenciados os livros Apostilas de Didática de Português, de Latim, de Inglês e de Desenho, podendo se tratar de um mesmo livro, como no caso do Apostilas de Didática Especial de Matemática e Apostilas de Didática de Matemática, publicados em 1958 e 1959 respectivamente, apenas com mudança no título e pequenas alterações gráficas na fonte do texto. No entanto, os quatro aqui apresentados não apresentam o mesmo número de páginas dos referenciados pelas autoras, indicando, portanto, a possibilidade de serem livros diferentes.

${ }^{15}$ Embora apresente esse título na capa, possivelmente trata-se do livro já relacionado por Baraldi e Gaertner (2013) como Didática Especial do Inglês.

${ }^{16}$ Disponível para download em: <https://repositorio.ufsc.br/handle/123456789/159286> (acesso em: 19 dez. 2017). Além desta, outras publicações da Cades também estão disponíveis para download no Repositório Institucional da Universidade de Santa Catarina (UFSC), <https://repositorio.ufsc.br/>: Didática Especial do Desenho (Julio Bruno) e os números 10 e 13 da revista Escola Secundária. 
DOI: https://doi.org/10.20396/zet.v27i0.8654273

Quadro 1 - Livros publicados pela Cades (complemento a Baraldi \& Gaertner, 2013). Conclusão.

\begin{tabular}{|l|c|c|}
\hline \multicolumn{1}{|c|}{ Título } & Autor & $\begin{array}{c}\text { Ano de } \\
\text { publicação }\end{array}$ \\
\hline $\begin{array}{l}\text { Documentário } n^{\circ} \text { 4: Problemas de Educação } \\
\text { Secundária }{ }^{17}\end{array}$ & Lourenço Filho & 1954 \\
\hline $\begin{array}{l}\text { Documentário } n^{\circ} \text { 6: Relatório sôbre o Ensino } \\
\text { Secundário na França e na Inglaterra }\end{array}$ & Gildasio Amado & 1955 \\
\hline $\begin{array}{l}\text { Documentário } n^{\circ} \text { 9: Apontamentos para a } \\
\text { história da administração federal do Ensino } \\
\text { Secundário }\end{array}$ & Geraldo Bastos Silva & 1957 \\
\hline Manual do Secretário & & \\
\hline
\end{tabular}

Fonte: Elaboração pessoal.

Na revista Escola Secundária, publicação desenvolvida e distribuída pela Cades, há ainda indicações sobre outras publicações, como uma série de volumes relacionados a um chamado Projeto da Seção de Prédios e Aparelhamento Escolar (SPAE) ${ }^{20}$; as Conclusões do $1^{\circ}$ Encontro de Educadores de Belo Horizonte; a série de cadernos "Atividades Extraclasse": Cinema educativo ${ }^{21}$; e a obra $A$ orientação profissional (de João de Oliveira Silva) ${ }^{22}$, das quais, entretanto, não localizamos informações mais detalhadas. Além disso, no jornal Tribuna da Imprensa há referência à publicação do Programa para os Exames de Suficiência (Estudo..., Tribuna da Imprensa, 1959), em forma de folhetos ${ }^{23}$, e sobre a distribuição pela Cades e pela Campanha de Aperfeiçoamento do Ensino Comercial (Caec) de um livreto

\footnotetext{
${ }^{17}$ Referenciado em Silva (1959).

${ }^{18}$ Referenciado em Silva (1959).

${ }^{19}$ Referenciado na revista Escola Secundária e em Silva (1959), nessa última obra aparece também com o título Apontamentos sôbre a evolução da administração federal do Ensino Secundário. Visto termos localizarmos referência a esses três documentários e um deles ser o de número 9, inferimos a possibilidade de existência de, pelo menos, nove deles.
}

${ }^{20}$ Ginásio Tipo I - projeto da SPAE, de um externato misto com capacidade para 200 alunos; Ginásio Tipo II publicação da SPAE, com o projeto de internato e semi-internato; Ginásio Tipo A - projeto da SPAE, para um colégio. Sobre esse último, em Mestres Aprendem... (Correio da Manhã, 1960), localizamos o título como Colégio Tipo A, nessa mesma notícia também temos a indicação da publicação de Relação dos Estabelecimentos de Ensino Secundário de Todo o Brasil.

${ }^{21}$ Em Publicações Didáticas... (Correio da Manhã, 1960) indica-se a publicação de um dos Cadernos de Atividades Extraclasse direcionado ao cinema.

22 Além desses, apontavam-se os livros O fenômeno da repetência nos Ginásios de Pôrto Alegre (Leonel Correia e Martrés Dubois) e os Anais do II Congresso do Ensino de Matemática, mas localizamos ambos como publicações realizadas no Rio Grande do Sul, o primeiro na Pontifícia Universidade Católica do Rio Grande do Sul e o segundo tendo apenas o registro da cidade (Porto Alegre). Além disso, ainda há duas monografias premiadas no IV Concurso Dia do Professor que, possivelmente, foram publicadas, visto todas as demais terem sido: Didática especializada de Francês (de Maria Alves Velloso) e Aspectos da didática de Geografia (de Paulo Fernando de Araújo Lago). Quanto a esta última, na listagem apresentada por Baraldi e Gaertner (2013) aparece uma publicação desse autor com o título Didática Especial de Geografia, que pode, talvez, se tratar da mesma obra.

${ }^{23}$ Em 1957 localizamos referência da publicação, pela Cades, de nove folhetos com os programas dos Exames de Suficiência, que serviam de guia aos candidatos (A Cades publica..., Imprensa Popular, 1957). 
DOI: https://doi.org/10.20396/zet.v27i0.8654273

intitulado Ensino de Contabilidade - aspectos metodológicos (Professôres marcam..., Tribuna da Imprensa, 1959). Ainda, em Inep (1980) há uma referência ao livro Uma experiência de teatro na Escola Secundária, de Hilton Carlos de Araújo ${ }^{24}$, com data de publicação de 1974, MEC/Cades Porto Alegre, enquanto as demais obras são distribuídas a partir do Rio de Janeiro.

Também não localizamos, específica e exatamente, a quantidade de impressões de cada livro publicado. No entanto, notícia publicada no Diário de Notícias dá conta de que do livro Nomenclatura Gramatical Brasileira, em um primeiro momento, foram distribuídos 1.000 exemplares e mais 2.000 em uma segunda etapa (Não terá..., Diário de Notícias, 1959). Já os livros Problemas da Sala de Aula, Didática da Matemática, Biblioteca Escolar e II Simpósio de Orientação Educacional, publicados em 1960, tiveram tiragem inicial de 3.000 exemplares cada, e da obra A Elaboração da nomenclatura gramatical brasileira foram produzidos 2.000 exemplares (Publicações didáticas..., Correio da Manhã, 1960). Essas informações nos dão uma dimensão quantitativa dessa tática editorial da Cades.

Os livros eram divulgados na revista Escola Secundária e em jornais de ampla circulação, como, por exemplo, o Correio da Manhã que, em uma edição de 1960, informava sobre a distribuição gratuita dos livros a todos que os solicitassem. Essas notícias aproveitavam para enfatizar a importância dos materiais produzidos, valorizando-os.

Apesar dessas tantas divulgações servirem como recurso para promover o Ensino Secundário e, por extensão, a própria Cades, não se pode deixar de notar alguns descuidos nessa iniciativa, como anúncios de uma mesma obra com títulos diferentes. Além disso, percebemos a ausência de um padrão nas publicações. Por exemplo, os livros Apostilas de Didática Especial de Matemática e Apostilas de Didática de Matemática, apesar dos títulos diferentes, são uma mesma obra reimpressa com alteração no título. Também o Didática Especial de Matemática, de Manoel Jairo Bezerra, teve seu título alterado para Didática de Matemática em sua segunda edição, permanecendo, entretanto, o título original na folha de rosto. Há ainda o livro de Maria Edmée de Andrade Jacques da Silva, que em sua capa traz o título Didática da Matemática e, na folha de rosto, A Didática da Matemática no Ensino Secundário. Esses descuidos editoriais implicam uma dificuldade adicional a quem deseja estudar esse acervo.

Percebemos que a divulgação desses materiais era mais intensa em jornais da então capital, a cidade do Rio de Janeiro, onde também estava sediada a Campanha, o que favorecia prioritariamente os professores cariocas em detrimento dos professores leigos do interior do país ${ }^{25}$.

Os livros foram organizados como parte do projeto maior da Cades, voltado à assistência ao professor. Assim, tinham como público alvo, principalmente, professores leigos do interior e alunos dos cursos de orientação para os exames de suficiência promovidos

${ }^{24} \mathrm{O}$ autor indica que esta foi uma publicação elaborada para atender à solicitação da Cades.

${ }^{25}$ Atrelado a isso, tem-se que o costume da leitura, de modo geral, já se dava de maneira mais intensa no Rio de Janeiro e outras grandes capitais, onde havia maior tradição editorial. 
DOI: https://doi.org/10.20396/zet.v27i0.8654273

pela própria Campanha, mas também atendiam aos orientadores educacionais e alunos de cursos dessa natureza, estudantes de Faculdades de Filosofia, diretores, educadores e profissionais do Ensino Secundário em geral. Os livros, de distribuição gratuita, eram bastante respeitados, principalmente por serem publicações oficiais, apoiadas pelo Ministério da Educação e Cultura - MEC (Rocco, 2010).

Quanto ao tratamento gráfico, as obras eram encadernadas em brochura, seguindo a imensa maioria dos materiais voltados à comunicação de massa que ganhou força no século XX (Lopes, 2015), tinham uma aparência simples, com uma diagramação limpa, com poucas figuras e cores, o que minimizava os custos (Hallewell, 1985). O papel utilizado era bom, tanto que até os dias atuais, passados cerca de sessenta anos das primeiras edições, em geral elas ainda se mantêm em ótimo estado.

As capas das obras seguiam certo padrão gráfico. De modo geral, eram "limpas", sem muitas cores, detalhes ou ilustrações. Quando havia, as ilustrações eram simples, seguindo modelos geométricos relativamente usuais visando a identificar a área do conhecimento em questão ${ }^{26}$. As capas mais "simples", não tão detalhadas, seguem a mesma linha gráfica dos livros didáticos da época, aos quais se reservava fundamentalmente a "sobriedade da transmissão de conteúdos curriculares e a consideração de que seu público não pediria mais do que isso. Para as vendas, se contava com a autoridade intelectual do autor e a seriedade de seu texto, dispensando investimento em capas como atrativo" (Moraes, 2010, p.44). No caso das publicações da Cades, além da autoridade intelectual do autor, havia a chancela oficial do MEC.

Usualmente os livros de uma mesma coleção traziam capas bastante similares, cuja diagramação permitia a rápida identificação da obra com o acervo produzido pela e para a Campanha. Das coleções produzidas, podemos citar: Apostilas de Didática; Concurso Dia do Professor; Como ensinar... no Curso Ginasial; Fichas Técnicas; Roteiros de conteúdo e didática das disciplinas do Ginásio ${ }^{27}$; Súmulas para os Cursos de Orientação; Anais de eventos; e Cadernos de Orientação Educacional ${ }^{28}$, todas elas formadas por livros que abrangiam as variadas disciplinas que integravam os Programas do Ensino Secundário. Além das Coleções havia, também, livros avulsos.

As capas normalmente traziam em sua composição o título, a editora e, por vezes, o nome do autor ${ }^{29}$, informações essenciais para que o leitor soubesse ser aquele um material

\footnotetext{
${ }^{26}$ Essas capas com figuras que remetem à área são mais frequentes na fase inicial de publicação da Cades, sendo posteriormente substituídas por figuras geométricas. Uma possibilidade que aventamos para essa substituição, além da organização de um padrão, é que as figuras pouco acrescentavam, aparecendo como secundárias em relação ao título, não estendendo seu significado, nem facilitando seu entendimento (Moraes, 2010).

27 Estes eram destinados, especialmente, aos alunos dos cursos de férias oferecidos pela Cades (Últimas..., Diário de Notícias, 1962).

28 Direcionados, principalmente, aos Orientadores Educacionais e aos alunos dos cursos desta natureza (Últimas..., Diário de Notícias, 1962).

${ }^{29}$ Quando registrado na capa da obra, o nome do autor era bastante destacado na diagramação, sendo apenas menos visível que o título do livro.
} 
DOI: https://doi.org/10.20396/zet.v27i0.8654273

"oficial", produzido pela Cades/MEC. Os autores da Cades, em geral, eram professores de conhecidos colégios de reputação nacional, muitas vezes já autores de outros livros e artigos em revistas especializadas, como a Escola Secundária, por exemplo.

Os livros têm uma linguagem de fácil compreensão, sem muitos conceitos complexos ou palavras rebuscadas. Apresentam certo tom professoral, de ensino, e o frequente uso das formas verbais "deve" e "é", bem como do substantivo "obrigação", revelando certa intenção prescritiva. Isso, aliado ao peso de estarem diretamente vinculados a uma Campanha governamental, intensificava a impressão de que as práticas e o modo de condução do ensino neles tratados eram os corretos a serem seguidos. A simplicidade na elaboração textual também servia adequadamente como fonte de formação aos professores leigos, que seriam por esses livros introduzidos ao estudo de conteúdos com os quais ainda não tinham tido o mínimo contato ${ }^{30}$. Quanto ao conteúdo, os livros "revelam um sistema de orientação de práticas, pois, por meio deles, ocorre uma seleção 'natural' acerca do que o professor deve aprender e, consequentemente, do que deve ensinar, e como fazê-lo" (Lopes, 2015, p.130).

As obras sempre acentuam a característica de estarem "de acordo com a legislação vigente", como também ocorria com os demais livros didáticos do mercado. Apesar de escritas por diferentes autores, elas, de modo geral, apresentavam um discurso harmônico. Mesmo com temáticas diversas, buscavam defender ideias e ideais próximos uns dos outros, uma atitude essencial para a criação de um modelo de professor secundário.

À época, as discussões sobre a Escola Nova e o ensino ativo permeavam os debates dos congressos nacionais e internacionais sobre educação e ensino, consequentemente se manifestando nas leis e instruções metodológicas apresentadas pelo governo e, como decorrência, nos materiais publicados pela Cades. As raízes dessa influência da Escola Nova na Campanha também podem, ao menos em parte, ser creditadas a Armando Hildebrand, diretor do Ensino Secundário de 1953 a 1956, criador e idealizador da Cades. Hildebrand teve sua formação influenciada por Anísio Teixeira e Lourenço Filho, precursores do movimento da Escola Nova no Brasil, em torno da década de 1920 (Lopes, 2015).

Havia temas comuns a vários livros, visando permitir que os leitores dessem sentido, criassem uma concepção sobre o Ensino Secundário paralela àquela promovida pelas políticas públicas. Tratavam das disciplinas a serem ensinadas, do que se esperava do professor, e amparavam metodológica e didaticamente a condução das aulas. O estudo dirigido $^{31}$, por exemplo, era frequentemente mencionado como tática para introduzir e fixar a

\footnotetext{
${ }^{30}$ Nas divulgações, os livros eram indicados como "fartos de acurada observação de estudiosos das questões ligadas ao bem ensinar, com temas de interêsse para os mestres, tal a soma de conhecimentos que oferecem, são narrados em linguagem simples, contendo apenas o absolutamente necessário para dinamizar o trabalho na sala de aula." (Didática..., Correio da Manhã, 1959, p.5), o que pode ser visto como uma tática de marketing para incentivar seu uso pelos professores, que além de lerem um material produzido por "um estudioso" do assunto, não encontrariam dificuldade na compreensão e não gastariam tempo lendo assuntos desnecessários e não relacionados à sua prática.

${ }^{31} \mathrm{O}$ estudo dirigido visava criar no "aluno o hábito do estudo, ensinando-lhe a estudar convenientemente", de modo que em cada estudo o pensamento do aluno fosse estimulado e orientado "para um determinado fim, prèviamente escolhido e bem caracterizado" (Chaves, 1960, p.45). Acreditava-se que, nesse tipo de ensino, o Zetetiké, Campinas, SP, v.27, 2019, p.1-18 - e019002

ISSN 2176-1744
} 
DOI: https://doi.org/10.20396/zet.v27i0.8654273

aprendizagem, tanto quanto era defendido como um elemento importante para incentivar a autonomia do aluno. As práticas diferenciadas e o uso de materiais didáticos também são recorrentemente tratados, com chamadas para o professor, sempre que possível, evitar o ensino expositivo que, se necessário, deveria ser recurso utilizado apenas por curtos períodos e, preferencialmente, em conjunto com outros métodos de ensino.

As atividades extraclasse, laboratórios, salas-ambiente e clubes das diferentes disciplinas eram apresentados ao professor como táticas interessantes. A motivação das aulas e dos alunos não era só tida como importante: era obrigatória. O planejamento didático recebe atenção especial em diversas obras da Cades. Nas avaliações, os testes objetivos eram valorizados como um substituto ou complemento das provas tradicionais/clássicas, sendo as avaliações mistas vistas como as mais eficientes.

O foco especial era colocado no papel do professor, mas servia para iluminar também o que era esperado do aluno, que deveria ser participante, e de sua formação, que seria especial e fundamentalmente humanística.

Sobre quem deveria ser o professor secundário, como deveria agir e se portar em sala e fora dela, também são várias as recomendações. O docente era visto como o principal agente motivacional, não tendo mais como único papel apresentar o conteúdo. Nesse período, o aluno passou a ser o principal foco do ensino, diante disso, não bastava que o professor dominasse o conteúdo, precisava saber trabalhar com os adolescentes, conhecendo sua biologia e psicologia, além de aspectos educacionais gerais e suas técnicas (Ebert, 195-?), de modo a desenvolver nos alunos habilidades e interesses que lhes permitiriam melhor adaptação à sociedade, intervindo na formação de suas personalidades.

\section{Os livros de Matemática}

Nos livros voltados ao ensino de Matemática, percebemos um discurso constante acerca da importância/papel dessa ciência no Ensino Secundário, seus objetivos e valores a serem promovidos. Da Matemática as obras ressaltam os aspectos de rigor e exatidão que deveriam ser cobrados dos estudantes, no entanto, de modo adequado, considerando os níveis de maturidade das turmas. Também são valorizadas a função e a aplicabilidade da Matemática em outras áreas do conhecimento e ao cotidiano, de modo geral, incentivando, a partir disso, um trabalho que hoje chamaríamos interdisciplinar.

Os planos de curso, de unidade didática e de aula, com técnicas e modelos para a elaboração desses planejamentos, também fazem parte dos livros de Matemática e são enfaticamente sugeridos aos professores/leitores. Há modelos muito esmiuçados e detalhados de modo a poderem ser facilmente reproduzidos. Do professor é chamada a atenção sobre a

\footnotetext{
aluno era mais autônomo em sua aprendizagem e o professor deixaria "de ser apenas um expositor dos conteúdos que os alunos, posteriormente, deveriam estudar sozinhos", passando "a ser mais ativo em sala de aula, organizando tarefas que deveriam ser executadas sob sua assistência ou de outros professores contratados para isso" (Baraldi \& Gaertner, 2013, p.75).
} 
DOI: https://doi.org/10.20396/zet.v27i0.8654273

importância do uso do livro didático, pontuando que a escolha desse material deveria atender às necessidades e objetivos pretendidos para cada turma ao longo do ano.

Aspectos importantes a serem considerados para o planejamento e condução das aulas são o tema central das obras: dever-se-ia, sempre, motivar a aprendizagem, apostando numa abordagem heurística ${ }^{32}$ em que o foco fosse o aluno, que por sua vez deveria ser cada vez mais ativo para buscar conhecimento. São detalhados alguns métodos didáticos, explicandose como a matéria deveria ser apresentada, quais elementos constituem uma exposição didática adequada, quais acessórios de ensino, ferramentas de grande importância no processo de ensino e aprendizagem ${ }^{33}$, usar; há sugestões, por exemplo, relativas à "sala especial de Matemática" e a uma biblioteca especializada ${ }^{34}$. Há também indicações de como o aluno deveria desenvolver suas atividades, valorizando a resolução de problemas, as tarefas e atividades extraclasse e, enfaticamente, abraçando o estudo dirigido. Sobre esses temas há grande detalhamento, indicação de como e o que deveria ser apresentado, em qual momento e sequência, por quanto tempo... Como regra geral, partir sempre do concreto para o abstrato. Quanto às possibilidades de avaliação da aprendizagem, cumpre ressaltar que testes objetivos eram tidos como mais adequados que as provas usuais, ainda que mais indicado ainda fosse um misto de abordagens. Há considerações muito minuciosas sobre, por exemplo, o modo de atribuir notas. Abordam-se, ainda, aspectos específicos do ensino de conteúdos matemáticos, com indicação de possíveis modos/sequências de apresentação e desenvolvimento dos assuntos e de técnicas para a fixação da aprendizagem. Ainda que sejam nítidas as referências à Escola Nova, à valorização da participação ativa do aluno, à ênfase em um ensino ativo, à opção por ter o aluno como centro do ensino e da aprendizagem, tendo o processo mais importância que os resultados finais, ao mesmo tempo percebe-se a defesa de posições mais conservadoras, centradas na defesa do rigor e da linguagem "correta" para o trabalho com a Matemática. Mas, também, é enfática a crítica à memorização - "memorizar sem compreender é um trabalho inútil e prejudicial à aprendizagem" (Chaves, 1960, p.98) e o que realmente importa é compreender o que foi ensinado.

A adolescência, suas particularidades, como trabalhar respeitando esse momento da vida dos jovens também é tema recorrente nos livros da Cades, inclusive nos de Matemática.

Uma análise dos Anais do III Congresso Brasileiro do Ensino da Matemática (Congresso Brasileiro de Ensino da Matemática, 1960), publicados pela Campanha, nos permite afirmar sobre a sincronia de concepções e o alinhamento das publicações cadesianas

\footnotetext{
${ }^{32}$ Nesse sentido, o método expositivo é bastante criticado, sendo aconselhado seu uso apenas em determinados momentos e, preferencialmente, acompanhado de outro mais dinâmico.

${ }^{33}$ Há uma explicação detalhada sobre seus usos, inclusive dos mais corriqueiros, como o quadro-negro e o apagador.

${ }^{34}$ Silva (1960) elabora uma listagem de aproximadamente 16 páginas, constituída por obras que poderiam auxiliar tanto professores quanto alunos no trabalho com diferentes temas em Matemática.
} 
DOI: https://doi.org/10.20396/zet.v27i0.8654273

com o que vinha sendo discutido em outros espaços, como, por exemplo, nos eventos sobre ensino $^{35}$.

Quanto à organização das referências, os livros não seguem um padrão - enquanto alguns apresentam uma listagem bem organizada desses materiais de apoio, outros sequer trazem referências ou citam outras obras ao longo de todo o texto.

\section{Os livros da Cades e um modelo de professor secundário}

Com a grande expansão do Ensino Secundário iniciado na década de 1940 e acentuada nos anos 1950, aumentou-se a necessidade de professores para atenderem a essa modalidade de ensino. Diante dessa situação em que havia um enorme quadro de professores leigos $^{36}$, fazia-se necessário um maior direcionamento da prática docente. Nesse sentido, as obras da Cades estavam de acordo com a legislação então vigente ${ }^{37}$ - a Lei Orgânica do Ensino Secundário, de 1942, e, posteriormente, a Lei de Diretrizes e Bases, de 1961 -, bem como com os Currículos Mínimos e as Instruções Metodológicas para o Ensino Secundário, fazendo coro com discussões mais amplas, como aquelas que ocorriam em eventos de âmbito nacional e internacional.

As reformas educacionais almejavam, assim, um novo Ensino Secundário para o qual seria necessário um novo professor secundário.

A formação do professor, portanto, era fundamental, pois o seu papel era essencial no processo de formação do cidadão. Prescrever o norte de formação com o objetivo de conformar o campo educacional, por meio de uma vasta rede de impressos, foi uma estratégia que seria alcançada pela produção de livros para a formação de professores. (Almeida Filho, 2008, p.124).

“Assim, a primeira medida a ser tomada na instrução deveria ser a utilização de um método de aprendizagem adequado ao desenvolvimento humano que, por sua vez, representava a antítese do que se praticava nas escolas brasileiras" (Valdemarin, 2010, p.54). Ao mesmo tempo, entre os anos 1940 e 1970, os impressos foram percebidos como espaços importantes de divulgação de estratégias comunicacionais, já que eram potentes meios de "conformar ideias e concepções de modelos pedagógicos e educacionais" (Almeida Filho, 2009, p.6). Disso decorre a tática da produção de materiais didáticos escritos, defendendo um novo ideário, calcado em métodos novos, humanísticos e bem dosados. Considerando as condições editoriais do período e a deficiência quanto à produção de livros voltados à

\footnotetext{
35 Nesse III Congresso e, portanto, nesse livro, foram discutidas questões relacionadas ao Movimento da Matemática Moderna.

36 “[...] recrutaram-se, às pressas, professôres improvisados, alguns mesmo (12\%) sem curso secundário completo. [...] Ainda hoje, decorridos quase 20 anos da criação dessas faculdades [Faculdades de Filosofia], sòmente cêrca de $16 \%$ dos 40.000 professôres secundários militantes tiveram a oportunidade de nelas adquirir uma adequada formação profissional: $84 \%$ dêsse exército de professôres são ainda autodidatas." (A Nossa revista, Revista Escola Secundária, 1957, p.6-8).

${ }^{37}$ Destaca-se nos livros, que estes seguem a legislação vigente, sendo esse também um modo de incentivar seu uso pelos leitores. Em alguns casos, essas informações constam do prefácio do livro, sendo acessíveis mesmo antes da leitura do corpo do texto.
} 
DOI: https://doi.org/10.20396/zet.v27i0.8654273

formação de professores leigos do Ensino Secundário ${ }^{38}$, o mercado foi então abastecido com mais de 100 obras, distribuídas gratuitamente, defendendo o modelo de professor necessário a essa nova perspectiva educacional. Os livros tinham como função precípua apoiar a formação do professor leigo atuante no Ensino Secundário, neles estando discutidos, fundamentalmente, não apenas conteúdos, mas os modos possíveis para a condução das aulas, servindo, assim, "como forma de regulação do que deveria ser o ensino secundário e da ação do professor que nele atuaria" (Baraldi \& Gaertner, 2010, p.166). Vistos como instrumento de formação pedagógica, “A preocupação com a prática do professor se sobrepõe ao conteúdo de ensino" (Oliveira \& Silva, 2006, p.6.318). Assim, os manuais pedagógicos exercem três funções distintas: "referencial (explicitam ou interpretam programas de ensino e seleções culturais), instrumental (propõem métodos de ensino, exercícios e atividades) e ideológica (atuam como instrumento de construção de identidades e aculturação)" (Valdemarin \& Campos, 2007, p.348).

Outra tática potente para que as intenções da Cades se realizassem pode ser percebida no modo como os materiais eram organizados, metodicamente, com prescrições detalhadas do que era e de como deveria ser o ensino, criticando posturas conservadoras arraigadas no meio escolar, visando que, com essa crítica, o professor repensasse e reavaliasse suas práticas, produzindo assim um "convencimento por meio de sua estrutura lógica e de seu discurso coerente” (Valdemarin, 2010, p.56).

O método de ensino é descrito com regras simples, que podem ser entendidas, memorizadas e repetidas por todos os leitores de modo a participarem, mesmo que discursivamente, das inovações pretendidas. A complexa fundamentação sobre a teoria do conhecimento é sintetizada em regras que, repetidas como um refrão em todos os manuais analisados ${ }^{39}$, acabam por caracterizar o método e revelam o estabelecimento de padrões profissionais, a normatização racional do trabalho docente, a transformação das teorias abstratas em rotinas "praticáveis". (Valdemarin, 2010, 59).

Sendo mais pragmáticos do que teóricos, os manuais produzidos atingiriam mais direta e rapidamente as salas de aula, influenciando a ação do professor. Eram prescritivos para atender de modo imediato as necessidades prementes dos professores leigos no preparo de suas aulas.

A intensa ênfase na metodologia de ensino e no uso de materiais didáticos promovem, ao fim e ao cabo, uma espécie de tecnicização do ensino. Incentivar o planejamento didático é tática compatível com o momento pelo qual passa o país, guiado pela política desenvolvimentista do governo de Juscelino Kubitschek. Assim, todas as tarefas educacionais deveriam ser "planejadas para garantir a eficiência e disciplina das atividades, adequando-as ao desenvolvimento social e econômico do país que então está pautado sobretudo na industrialização" (Silva, 2003, p.48).

\footnotetext{
38 Até que fosse iniciada a tática de produção editorial da Cades, a grande maioria das obras se destinava a estudantes das Escolas Normais e a professores do Ensino Primário. ${ }^{39}$ Apesar de não se tratarem dos mesmos materiais estudados por nós, nem voltados ao mesmo nível de ensino,
acreditamos que as considerações da autora são válidas também neste nosso caso.
} 
DOI: https://doi.org/10.20396/zet.v27i0.8654273

Considerar o professor como foco de seus livros, apontando sua importância no processo de ensino e aprendizagem, indicando-o como desejoso de se aperfeiçoar, valorizando seu esforço e apregoando que bem provavelmente esse professor já se portava de modo condizente com o que era sugerido nos livros são afirmações que constituem um discurso que opera favoravelmente para que o professor se abra para aceitar o que a ele é proposto. Essa valorização do docente, de sua função, de seu papel no ensino é, portanto, tática de convencimento, uma dentre as tantas táticas postas em movimento pela Cades.

Atribuir a responsabilidade pela melhoria do Ensino Secundário ao professor torna-se não um discurso que inferioriza e assujeita, mas que empodera: "Sem o professor, qualquer filosofia da educação será vã e vazia. Com sua colaboração, quaisquer que sejam as condições em que se realiza o processo educacional, sempre haverá possibilidades de sucesso." (Siqueira, 195-?, p.21).

Até mesmo as dimensões dos livros podem ser consideradas estratégicas, visto serem de pequeno porte, o que favorece

seu manuseio, portabilidade e armazenagem por quem o possui, além disso, a fonte utilizada para editá-lo proporciona uma leitura sem dificuldades. Como este Manual era destinado a professores, o mesmo poderia sempre estar acessível ao professor [...] sendo facilmente portátil e guardado em uma bolsa, mochila, ou pasta, por exemplo (Lopes, 2015, p.135).

Quanto à distribuição, deve-se reiterar a importância da divulgação, em jornais de ampla circulação e na revista Escola Secundária, sobre a produção das obras, sendo a gratuidade um importante fator para a boa circulação dos livros.

Esses, dentre outros fatores que pensamos ter discutido ao longo deste texto, permitem conceber a produção editorial da Cades como um recurso importante para a configuração de um novo modelo de Escola Secundária e de professor secundário, pois "organizavam o campo educacional, conformando a cultura escolar" (Almeida Filho, 2008, p.5). Outros fatores - que não podem ser discutidos neste artigo por escaparem de seu escopo - reforçam essa intenção da Cades relativa à formação de um novo professor para atuar em uma nova escola.

\section{Agradecimentos}

Os autores agradecem a Capes pela bolsa concedida para a realização deste estudo. Agradecem também à professora Doutora Ivete Maria Baraldi, orientadora principal dessa tese de doutorado que, devido a compromissos, não pode participar da elaboração deste artigo. A ela também agradecemos pelo acesso irrestrito ao seu acervo de livros da Cades.

\section{Referências}

A Cades publica todos os programas de Exames de Suficiência para 1958. (1957, dezembro 14). Imprensa Popular. Rio de Janeiro, p.4.

A Nossa Revista. (1957). Escola Secundária, (1), 5-9. 
DOI: https://doi.org/10.20396/zet.v27i0.8654273

Albuquerque Jr., D. M. (2007). História: a arte de inventar o passado. Bauru, SP: Edusc.

Almeida Filho, O. J. de. (2008). A Estratégia da produção e circulação católica do projeto editorial das coleções de Theobaldo Miranda Santos: (1945-1971). Tese de Doutorado em Educação. São Paulo: Pontifícia Universidade Católica de São Paulo.

Almeida Filho, O. J. de. (2009). Pedagogia Católica na Estratégia Editorial das Coleções de Theobaldo Miranda Santos. Anais do II Seminário Brasileiro Livro e História Editorial LIHED (pp.1-16). Rio de Janeiro.

Armando Hildebrand passa o cargo para Gildásio Amado. (1956, abril 5). Diário Carioca. Rio de Janeiro, p.3.

Baraldi, I. M., \& Gaertner, R. (2010). Contribuições da Cades para a Educação (Matemática) Secundária no Brasil: uma descrição da produção bibliográfica (1953-1971). Bolema, 23(35A), 159-183.

Baraldi, I. M.; Gaertner, R. (2013). Textos e contextos: um esboço da Cades na História da Educação (Matemática). Blumenau, SC: Edifurb.

Cades - Hildebrand, A. et al. (195-?). Como ensinar matemática no curso ginasial: manual para orientação do candidato a professor de curso ginasial no interior do país. Rio de Janeiro: MEC/Cades.

Chaves, J. G. (1960). Didática da matemática. Rio de Janeiro: Cades.

Congresso Brasileiro de Ensino da Matemática. (1960). Anais do $3^{\circ}$ Congresso Brasileiro de Ensino da Matemática. Rio de Janeiro: Cades.

Didática das disciplinas do curso médio. (1959, janeiro 30). Correio da Manhã. Rio de Janeiro, p.5, $2^{\circ}$ caderno.

Ebert, A. (195-?). O Professor de nível Secundário. In CADES - Z. de Menezes, et al. (Org.). Noções de didática geral e seus fundamentos (pp. 161-163). Rio de Janeiro: Cades.

Estudo de didática especial ao magistério. (1959, janeiro 29). Tribuna da Imprensa. Rio de Janeiro, p.4.

Garcia, T. M. F. B., \& Nascimento, F. E. do. (2009). A Didática e os manuais para ensinar a ensinar Física. Anais do IX Congresso Nacional de Educação e III Encontro Sul Brasileiro de Psicopedagogia (pp.8.634-8.645). Curitiba.

Hallewell, L. (1985). O Livro no Brasil: sua história. São Paulo, SP: T. A. Queiroz: Editora da Universidade de São Paulo. Tradução de Maria da Penha Villalobos e Lólio Lourenço de Oliveira.

Instituto Nacional de Estudos e Pesquisas Educacionais (INEP). (1980). Escolinha de Artes do Brasil. Brasília: MEC/Inep. Série Estudos e Pesquisas - 6.

Lopes, M. H. S. (2015). “Como Ensinar matemática no curso ginasial”: um manual da Cades e suas propostas para a formação de professores de matemática. Dissertação de Mestrado em Educação Matemática. Campo Grande: Fundação Universidade Federal de Mato Grosso do Sul.

Mestres aprendem organizar bibliotecas. (1960, maio 5). Correio da Manhã. Rio de Janeiro, p. $12,1^{\circ}$ caderno. 
DOI: https://doi.org/10.20396/zet.v27i0.8654273

Moraes, D. D. C. D. de. (2010). Visualidade do livro didático no Brasil: o design de capas e sua renovação nas décadas de 1970 e 1980. Dissertação de Mestrado em Educação. São Paulo: Universidade de São Paulo.

Morais, M. B. (2012). Peças de uma história: formação de professores de matemática na região de Mossoró (RN). Dissertação de Mestrado em Educação Matemática. Rio Claro: Universidade Estadual Paulista.

Não terá caráter obrigatório a nomenclatura gramatical do MEC. (1959, janeiro 21). Diário de Notícias. Rio de Janeiro, p.4, $2^{\mathrm{a}}$ seção.

Oliveira, M. C. A. de, \& Silva, M. C. L. da. (2006). Uma Análise comparativa da formação inicial de professores de Matemática e as capacitações para a implementação da Matemática Moderna em escolas paulistas nas décadas de 50 e 60. Anais do VI Congresso Luso-Brasileiro de História da Educação - Colubhe (pp. 6.312-6.321). Uberlândia.

Pontes, H. (1988). Retratos do Brasil: um estudo dos editores, das editoras e das "Coleções Brasilianas", nas décadas de 1930, 40 e 50. BIB (Revista Brasileira de Informação Bibliográfica em Ciências Sociais), Rio de Janeiro, (26), 56-89.

Presença da Cades também no interior. (1960, agosto 20). Jornal do Commercio. Rio de Janeiro, p. $2,1^{\circ}$ caderno.

Professôres marcam encontro para fazer escola mais viva. (1959, abril 10). Tribuna da Imprensa. Rio de Janeiro, p.7.

Publicações didáticas visando o aperfeiçoamento do ensino. (1960, setembro 20). Correio da Manhã. Rio de Janeiro, p.10, $2^{\circ}$ caderno.

Rocco, C. M. K. (2010). Práticas e discursos: análise histórica dos materiais didáticos no ensino de Geometria. Dissertação de Mestrado em Educação Científica e Tecnológica. Florianópolis: Universidade Federal de Santa Catarina.

Schmidt, M. A. B. (2006). Estado e construção do código disciplinar da Didática da História. Perspectiva, Florianópolis, 24(2), 709-729.

Silva, G. B. (1959). Introdução à crítica do Ensino Secundário. Rio de Janeiro: Cades.

Silva, M. E. de A. J. da. (1960). A Didática da matemática no Ensino Secundário. Rio de Janeiro: Cades.

Silva, V. B. da. (2003). Uma história das leituras para professores: análise da produção e circulação de saberes especializados nos manuais pedagógicos (1930-1971). Revista Brasileira de História da Educação, (6), 29-57.

Silva, V. B. da. (2005). Saberes em viagem nos manuais pedagógicos: construções da escola em Portugal e no Brasil (1870-1970). Tese de Doutorado em Educação. São Paulo: Universidade de São Paulo.

Siqueira, C. R. (195-?). Função e objetivos da Escola Secundária brasileira. In CADES - A. Hildebrand, et al. (Org.). Como ensinar matemática no curso ginasial: manual para orientação do candidato a professor de curso ginasial no interior do país (pp.9-21). Rio de Janeiro: MEC/Cades.

Últimas publicações da Cades. (1962, abril 1). Diário de Notícias. Rio de Janeiro, p.4, $5^{\mathrm{a}}$ seção. 
DOI: https://doi.org/10.20396/zet.v27i0.8654273

Valdemarin, V. T. A. (2010). Construção do objeto de pesquisa. In Silva, M., \& Valdemarin, V. T. (Org.). Pesquisa em educação: métodos e modos de fazer (pp.47-66). São Paulo, SP: Cultura Acadêmica.

Valdemarin, V. T., \& Campos, D. G. do S. (2007). Concepções pedagógicas e método de ensino: o manual didático Processologia na Escola Primária. Paidéia (online), 17(38), 343-356.

Valente, W. R. (2007). História da Educação Matemática: interrogações metodológicas. Revemat - Revista Eletrônica de Educação Matemática: UFSC, 2(1), 28-49. 